\title{
Sandflies (Diptera: Psychodidae) in a focus of visceral leishmaniasis in White Nile, Sudan
}

\author{
Sally Osman Widaa ${ }^{1,2}$, Khalid Awadelkarim Ahmed', Amel Ahmed Elsheikh Bari', \\ Mayada Mohmmedelhassan Ali', Mihad Abdelaal Ibrahim', Mohammed Ahmed Bashir', \\ Ahmed Hamid Awadelkarim Mastour ${ }^{3}$, Zakkiah Algali Yagi ${ }^{4}$, Mo'awia Mukhtar Hassan¹/+
}

\author{
1'Department of Vector Biology and Biomedical Studies, \\ Tropical Medicine Research Institute, National Centre for Research, PO Box 1304, Khartoum, Sudan \\ ${ }^{2}$ Blue Nile National Institute for Communicable Diseases, University of Gezira, Wad Madani, Sudan \\ ${ }^{3}$ Malaria Control Programme, White Nile State Ministry of Health, Kosti, Sudan \\ ${ }^{4}$ Malaria, Schistosomiasis and Leishmaniasis Administration, Federal Ministry of Health, Khartoum, Sudan
}

\begin{abstract}
Visceral leishmaniasis (VL) has been known to occur since the 1980s on the western bank of the White Nile River (Central Sudan), $150 \mathrm{~km}$ south of Khartoum, and has resulted in high mortality. The most recent outbreak of the disease in this area began in 2006. Entomological surveys were carried out during May 2008, June 2010 and May and July 2011 in the White Nile area. Sandflies were collected using Centers for Disease Control light traps and sticky oil traps in the village of Kadaba and the nearby woodland. Phlebotomus females were dissected for the presence of Leishmania promastigotes. A total of 17,387 sandflies, including six species of Phlebotomus and 10 species of Sergentomyia, were identified. The Phlebotomus species recorded were Phlebotomus orientalis, Phlebotomus papatasi, Phlebotomus bergeroti, Phlebotomus duboscqi, Phlebotomus rodhaini and Phlebotomus saevus. P. orientalis was collected in both habitats. The relative abundance of $\mathrm{P}$. orientalis in the woodland habitat was higher than that recorded in the village habitat. In the woodland habitat, there was a notable increase in the relative abundance of P. orientalis during the surveys conducted in 2008 and 2010 compared to 2011. None of the 311 P. orientalis females dissected were infected with Leishmania promastigotes, although relatively high parous rates were recorded in both habitats. Based on the distribution of P. orientalis recorded in this study, this species is the most likely vector of VL in the endemic focus in the White Nile area. Further investigation is required to elucidate the seasonal abundance and distribution of the vector, as well as the transmission season of VL in both habitats so that appropriate control strategies for the vector can be designed.
\end{abstract}

Key words: VL - Phlebotomus orientalis - White Nile - Sudan

Human visceral leishmaniasis (VL) (kala-azar) has been known to exist in Sudan since the beginning of 19th century (Zijlstra \& El-Hassan 2001). The disease is endemic in several regions over a wide area, including the eastern and the former southern part of the country (the new South Sudan Republic) with small foci in the Nuba Mountains and the state of Darfur, in western Sudan, and in Kapoita at the former southern Sudan/Kenyan border (Zijlstra \& El-Hassan 2001). In the past, several outbreaks of the disease occurred in Sudan. In the 1950s, an outbreak of VL was reported from El-Jazeera Abba north to Kosti in the central part of Sudan on the eastern bank of White Nile, $300 \mathrm{~km}$ south of Khartoum (Satti 1958). Since that time, no VL cases were reported until the 1980s, when an outbreak of VL struck four villages (Elkitair, Shatawi, Kadaba and Wad Elsafori) on the western bank of the White Nile, approximately $150 \mathrm{~km}$ south of Khartoum (Ahmed et al. 1988). During this outbreak, the

\footnotetext{
Financial support: EMRO/TDR (SGS 08/179), NCR/Sudan + Corresponding author: nuratagi@gmail.com

Received 18 August 2011

Accepted 10 February 2012
}

disease appeared to be more severe and killed over 100 individuals, mostly children (Ahmed et al. 1988). Generally, it has been thought that this outbreak was associated with the migration of labourers from the endemic focus of VL in the Gedarif area to the woodland area around the villages to prepare lands for agricultural schemes. However, this focus remained dormant until October 2006, during which more than 150 cases of VL, mostly children, were admitted to various hospitals in Khartoum (Khalil et al. 2008). Following the last outbreak, this area has become an endemic focus of VL, with an annual incidence of 20-30 cases.

Sudanese VL is caused by the Leishmania donovani complex and transmitted by Phlebotomus orientalis (Ashford et al. 1992). This species is known as the main vector of VL in the eastern and the former southern part of Sudan (Ashford et al. 1992, Hassan et al. 2008). It has been suggested that $P$. orientalis prefers areas characterised by the presence of Acacia seyal/Balanites aegyptiaca vegetation, which grows on dark black cotton soil (Elnaiem et al. 1998). However, P. orientalis has been found in a semi-desert area (Hassan et al. 2007). In eastern Sudan, $P$. orientalis has been found to be infected with $L$. donovani from late March-June, which indicates that the transmission of VL occurs during this time of the year (Elnaiem et al. 2001, Hassan et al. 2008). 
No data have previously been collected on the sandfly vector(s) from this focus of VL in the White Nile area. Bearing in mind the importance of VL to public health and the recent outbreak in the White Nile area, including the village of Kadaba, entomological surveys were carried out to investigate the prevalence of the sandfly vector(s) and to determine their rate of infection with Leishmania parasites so as to establish the vector of VL in the area.

\section{MATERIALS AND METHODS}

Study area - A revived focus of VL has occurred in the village of Kadaba (Khalil et al. 2008). The village is located on the western bank of the White Nile $\left(32^{\circ} 14^{\prime} \mathrm{E}\right.$ $14^{\circ} 72^{\prime} \mathrm{N}$ ), $150 \mathrm{~km}$ south of Khartoum (Figure). The ecology of the area has been described by Wickens (1991). In general, the area is flat and covered by an alluvium of silt clay soil, with black cracking clay soil on the river bank and sandy soil in the village. The area is entirely located in a semi-desert region with three distinct seasons: winter (November-February), summer (March-June) and autumn (July-October), with an estimated annual rainfall of $250-350 \mathrm{~mm}$. The vegetation of the area is dominated by desert scrub vegetation (i.e., Acacia tortilis and Acacia mellifera) and grassland (perennial grasses). However, on the clay soil along the river, $7 \mathrm{~km}$ to the west, the area is occupied by low rainfall savannah vegetation $(A$. seyal, B. aegyptiaca and Acacia nilotica). This area is completely flooded during the main flood season of the White Nile (August-October). The savannah woodland is widely destroyed by families who use the woodland for cultivation and grazing during the summer months.

Collection of sandflies - We carried out these surveys during months when a high prevalence of sandflies and high infection rates of $P$. orientalis by $L$. donovani have been reported in eastern Sudan (Elnaiem et al. 1997, Hassan et al. 2008). Sandflies were collected using Centers for Disease Control (CDC) light traps (John Hock Co, Gainsville, FL, USA) in Kadaba and the $A$. seyal/B.

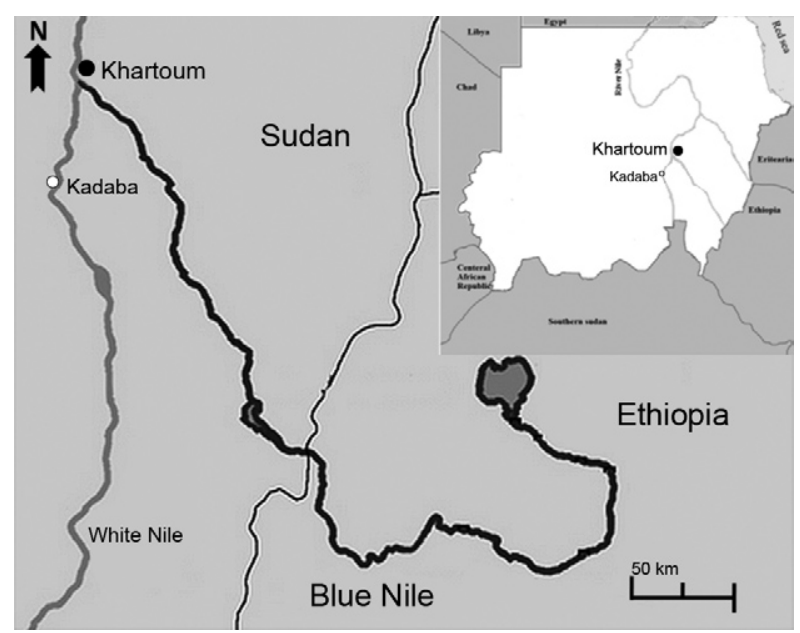

A map showing the study area [Kadaba (o)] in White Nile, Sudan. aegyptiaca woodland (2-6 km from the village) through four surveys carried out during May 2008, June 2010, May 2011 and June 2011. Sandflies were collected from the village only during the first survey (May 2008). All light traps were set at outdoor sites, with the exception of six traps that were set at indoor sites in the village. The outdoor trapping habitats were located near animal sheds in the Acacia/Balanites forest and outside houses in the village, whereas the indoor habitats included rooms inside houses in the village. In each survey, six light traps were used every night. The light traps were set $30 \mathrm{~cm}$ above the ground between 06:00 pm-06:00 am. In these surveys, sandflies were collected for four-eight consecutive nights. A total of 156 light traps (48, 48, 24 and 36 traps in 4 surveys) were set over 26 nights. Of the 48 light traps used in 2008, 30 traps were in the woodland and 18 traps were in the village. Additionally, limited numbers of sticky oil traps, which were prepared using Xerox paper $(20 \times 20 \mathrm{~cm})$ coated with castor oil on both sides, were used to collect sandflies in the village and woodland during 2008 and 2010. In 2008, only 20 sticky oil traps were used (10 traps/night) for two consecutive nights outside near houses in the village, whereas in 2010, 30 traps were used (10 traps/night) in the woodland, which is dominated by $A$. seyal and B. aegyptiaca. The captured sandflies were preserved in $70 \%$ ethanol for subsequent species identification.

Determination of infection rates, abdominal status and parous rates of Phlebotomus sandflies - Female Phlebotomus sandflies were dissected under a microscope as described by Elnaiem and Osman (1998). Briefly, the sandflies were killed in sterile normal saline, drops of detergent were added and then the flies were rinsed twice in normal saline. The gut of each female sandfly was removed along with the ovaries and placed in a drop of sterile saline on a microscope slide. Then the guts (i.e., the foregut, midgut and hindgut) of the dissected females were examined under a phase contrast microscope at $40 \mathrm{x}$ 10 magnification for the presence of Leishmania promastigotes. Primary attention was given to the midgut.

Parous females were distinguished from nulliparous flies by the observation of the follicular relics of the ovaries (Magnarelli et al. 1984) and the appearance of the accessory glands and the genital atrium (Añez \& Tang 1997). Briefly, a few drops of normal saline were added to the dissected ovaries on the glass slides. The ovaries were then examined under a phase contrast microscope at $40 \times 10$ magnification. Parous flies were recognised by large, dense, pale and stretchable ovaries (looselypacked ovarioles in the ovaries), opacity due to yellow granulated secretions in the accessory glands and the folded edges of the genital atrium armature. Nulliparous flies were recognised by the presence of small, clear, refractile, transparent, shiny and fragile ovaries (tightlypacked ovarioles in the ovary) and unfolded edges of the genital atrium armature. Two of the above mentioned character states were used to distinguish between parous and nulliparous flies. Moreover, additional un-dissected Phlebotomus females were examined for abdominal status and the numbers of unfed, fresh-blood fed and gravid (and half-gravid) sandflies were recorded. 
Mounting and identification of sandflies - Upon dissection of sandflies in the field, the head and the last two segments were transferred to a separate slide, mounted in Berlese's medium under individual glass cover slips and identified using the morphology of the male genitalia and female spermathecae (Abonnenc \& Minter 1965). Using a phase contrast microscope (at $40 \times 10$ magnification), sandflies of subgenus Phlebotomus (Phlebotomus papatasi, Phlebotomus bergeroti and Phlebotomus duboscqi), which have morphologically similar females, were separated by the size and shape of the atrium armature (P. papatasi and P. duboscqi) (Pesson et al. 1994) and the relative length of the ascoid on the fourth antennal segment (P. papatasi and P. bergeroti) (Lane \& Fritz 1986). In the laboratory, the alcohol-preserved sandflies were mounted and then identified as described above.

\section{RESULTS}

A total of 17,387 sandflies were collected from the woodland (16,791 flies) and Kadaba village (596 flies) during four surveys. The collection included six species of Phlebotomus and 10 of Sergentomyia. These were $P$. orientalis, P. papatasi, P. bergeroti, P. duboscqi, Phlebotomus saevus, Phlebotomus rodhaini, Sergentomyia clydei, Sergentomyia schwetzi, Sergentomyia lesleyae, Sergentomyia squamipleuris, Sergentomyia antennata, Sergentomyia bedfordi, Sergentomyia africana, Sergentomyia adleri, Sergentomyia hunti and Sergentomyia affinis (Table I). S. clydei (32.9\%) and S. squamipleuris $(26.70 \%)$ comprised the majority of the total catch (Table I). All six Phlebotomus species were obtained from the woodland, while only $P$. orientalis and $P . p a-$ patasi were recorded in the village habitat. Of the total collection, $1,521(8.8 \%)$ of the specimens were identified as $P$. orientalis: $1,469(8.40 \%)$ from the woodland and $52(0.30 \%)$ from the village. No Phlebotomus sandflies were collected from indoor sites.

The woodland contained more $P$. orientalis than the village habitats (Table II). The average density of $P$. orientalis per light trap was 10.3 flies/trap/night (overall density/light trap) in the woodland and 2.6 flies/trap/ night in the village (Table II). When sticky oil traps were used, the average density of $P$. orientalis per oil trap was 1.7 flies/trap/night in the woodland and 0.3 flies/trap/ night in the village. For the woodland habitat, there was a clear tendency toward an increased density of $P$. orientalis during the surveys performed in 2008 and 2010 compared to the surveys performed in 2011 (Table II). The highest number of $P$. orientalis sandflies per light trap was $13.2 \mathrm{flies} / \mathrm{trap} /$ night in 2011 (13.3 flies/trap/night in May and $12.8 \mathrm{flies} /$ trap/night in June) (Table II).

The results of dissection of female Phlebotomus sandflies from both habitats revealed no Leishmania infection in 311 female $P$. orientalis (281 from the woodland and 30 from the village), 79 female $P$. papatasi, 24 female $P$. duboscqi, six $P$. bergeroti and three female $P$. saevus. With the exception of $P$. orientalis, all other Phlebotomus females dissected in this study were collected from the woodland. Of the 281 dissected $P$. orientalis from the woodland, 69, 109 and 103 were collected during May 2008, June 2010 and June 2011, respectively.

Table III illustrates the abdominal status and parous rates of the $P$. orientalis during the dissection of $P$. orientalis females in the present study. Of the 560 P. ori-

TABLE I

The species and number of sandflies collected using light traps and oil traps from White Nile area during 2008,2010 and 2011

\begin{tabular}{|c|c|c|c|}
\hline \multirow[b]{2}{*}{ Species } & \multicolumn{3}{|c|}{ Sandflies collected } \\
\hline & $\begin{array}{c}\text { Woodland } \\
\mathrm{n}(\%)\end{array}$ & $\begin{array}{c}\text { Village } \\
\mathrm{n}(\%)\end{array}$ & $\begin{array}{l}\text { Total } \\
\mathrm{n}(\%)\end{array}$ \\
\hline Phlebotomus (Larroussius) orientalis & $1,469(8.40)$ & $52(0.30)$ & $1,521(8.80)$ \\
\hline Phlebotomus (Phlebotomus) papatasi & $1,597(9.20)$ & $6(0.03)$ & $1,603(9.20)$ \\
\hline Phlebotomus (Phlebotomus) bergeroti & $24(0.14)$ & $0(0)$ & $24(0.14)$ \\
\hline Phlebotomus (Phlebotomus) duboscqi & $78(0.5)$ & $0(0)$ & $78(0.50)$ \\
\hline Phlebotomus (Paraphelobotomus) saevus & $8(0.05)$ & $0(0)$ & $8(0.05)$ \\
\hline Sergentomyia (Sintonius) clydei & $5,507(31.7)$ & $224(1.30)$ & $5,731(32.9)$ \\
\hline Sergentomyia (Sintonius)adleri & $111(0.60)$ & $0(0)$ & $111(0.60)$ \\
\hline Sergentomyia (Sintonius) affinis & $148(0.85)$ & $0(0)$ & $148(0.85)$ \\
\hline Sergentomyia (Grassomyyia) squamipleuris & $4,471(25.70)$ & $181(1.04)$ & $4,652(26.70)$ \\
\hline Sergentomyia (Sergentomyia) schwetzi & $1,916(11.02)$ & $133(0.76)$ & $2,049(11.70)$ \\
\hline Sergentomyia (Sergentomyia) antennata & $925(5.30)$ & $0(0)$ & $925(5.30)$ \\
\hline Sergentomyia (Sergentomyia) bedfordi & $72(0.41)$ & $0(0)$ & $72(0.41)$ \\
\hline Sergentomyia (Parrotomyia) africana & $361(2.10)$ & $0(0)$ & $361(2.10)$ \\
\hline Sergentomyia (Parvidens) lesleyae & $12(0.07)$ & $0(0)$ & $12(0.07)$ \\
\hline Sergentomyia (Neophlebotomus) hunti & $92(0.53)$ & $0(0)$ & $92(0.53)$ \\
\hline Total & $16,791(96.6)$ & $596(3.4)$ & 17,387 \\
\hline
\end{tabular}


entalis females collected from the woodland, $381(68 \%)$ were unfed, 77 (13.8\%) were freshly fed and $102(18.2 \%)$ were gravid or half-gravid females. Of the 281 P. orientalis females dissected in the woodland, $182(64.8 \%)$ were parous: $42 / 69$ (60.1\%), 76/109 (69.7\%) and 65/103 (61.1\%) in 2008, 2010 and 2011, respectively. Similarly, of the 42 female $P$. orientalis obtained from Kadaba, 29 $(69.1 \%)$ were unfed, four $(9.5 \%)$ were freshly fed and nine $(21.4 \%)$ were gravid or half-gravid females. Of the $30 P$. orientalis females obtained the village and dissected to determine their ovarian state, $19(63.3 \%)$ were parous.

\section{DISCUSSION}

In the present study, entomological surveys were carried out in the village of Kadaba and the surrounding woodland, dominated by $A$. seyal and B. aegyptiaca trees, during May 2008, June 2010 and May and June 2011. No surveys were done from November-April because the woodland is inaccessible due to flooding with water from the White Nile until late March, although the main flooding season of the river is known to be from mid-August through October. The results of these surveys on sandflies are shown in Table I. A total of 17,387 sandflies, including six Phlebotomus species ( $P$. orientalis and P. papatasi, $P$. bergeroti, $P$. duboscqi, P. saevus and $P$. rodhaini), were collected from the study area in White Nile. The species recorded here are consistent with previous reports in other parts of Sudan (Kirk \& Lewis 1951, Quate 1964, Hoogstraal \& Heyneman 1969, Elnaiem et al. 1997, Lambert et al. 2002, Hassan et al. 2007).

Ecologically, the woodland habitat in our study area is generally similar to the known VL-endemic areas in eastern Sudan, which are dominated by $A$. seyal/B. aegyptiaca thickets that grow on black cotton clay soil. $P$. orientalis is known to thrive best in such habitats (Elnaiem et al. 1998). Considering these ecological characteristics, it may be that the transmission of VL in this area is restricted to the $A$. seyal/Balanites woodland, as is found in other endemic foci (Elnaiem et al. 1998, Hassan et al. 2008). However, in this study, P. orientalis was encountered in both the A. seyal/B. aegyptiaca woodland and the village habitat. To understand the epidemiology of VL, it is important to collect $P$. orientalis from both habitats. P. orientalis is the main vector of $L$. donovani in eastern Sudan and the former southern Sudan (Ashford et al. 1992, Hassan et al. 2008); therefore, the occurrence of this species in the woodland area and the village might suggest that transmission of the disease could be possible in each habitat. Similarly, in eastern Sudan, it has been suggested that transmission of VL occurs both in the woodland area and inside the village (Elnaiem et al. 1997, Hassan et al. 2004). It is notable that, in eastern Sudan, the transmission of VL starts in late March and continues through late June in the woodlands of Dinder

\section{TABLE II}

Numbers of Phlebotomus orientalis sandflies collected by light traps from woodland Acacia seyal/Balanites aegyptiaca and Kadaba village in White Nile, Sudan

\begin{tabular}{|c|c|c|c|c|c|c|}
\hline \multirow[b]{2}{*}{ Sites } & \multicolumn{2}{|c|}{ May 2008} & \multicolumn{2}{|c|}{ June 2010} & \multicolumn{2}{|c|}{ May and June $2011^{a}$} \\
\hline & $\begin{array}{l}\text { Traps } \\
\text { (n) }\end{array}$ & $\begin{array}{l}\text { Sandflies/trap } \\
\text { (n) }\end{array}$ & $\begin{array}{l}\text { Traps } \\
\text { (n) }\end{array}$ & $\begin{array}{l}\text { Sandflies/trap } \\
\text { (n) }\end{array}$ & $\begin{array}{l}\text { Traps } \\
\text { (n) }\end{array}$ & $\begin{array}{c}\text { Sandflies/trap } \\
\text { (n) }\end{array}$ \\
\hline Kadaba village & 18 & 2.6 & NA & NA & NA & NA \\
\hline Woodland & 30 & 8.1 & 48 & 8.0 & 60 & 13.2 \\
\hline
\end{tabular}

$a$ : the relative abundance of $P$. orientalis (13.3 and $12.8 \mathrm{flies/trap/night).} \mathrm{The} \mathrm{overall} \mathrm{number} \mathrm{of} \mathrm{sandflies/trap/night} \mathrm{in} \mathrm{woodland}=$ 10.3 flies/trap/night. NA: no data was collected.

TABLE III

Parous rates and abdominal status of Phlebotomus orientalis female determined during 2008, 2010 and 2011

\begin{tabular}{lccccc}
\hline & \multicolumn{5}{c}{ P. orientalis } \\
\cline { 2 - 6 } Habitat & $\begin{array}{c}\text { Examined }^{a} \\
(\mathrm{n})\end{array}$ & $\begin{array}{c}\text { Dissected } \\
(\mathrm{n})\end{array}$ & $\begin{array}{c}\text { Fresh blood-fed } \\
\mathrm{n}(\%)\end{array}$ & $\begin{array}{c}\text { Gravid } \\
\mathrm{n}(\%)\end{array}$ & $\begin{array}{c}\text { Parous } \\
\mathrm{n}(\%)\end{array}$ \\
\hline $\begin{array}{l}\text { Village } \\
\text { Woodland }\end{array}$ & 42 & 30 & $4(9.5)$ & $9(21.4)$ & $19(63.3)$ \\
\hline Total & 560 & 281 & $77(13.8)$ & $102(18.2)$ & $182(64.8)$ \\
\hline
\end{tabular}

the parous rate was calculated from the dissected $P$. orientalis and the percentage of abdominal status was calculated from the examined females. 
National Park, which are dominated by $A$. seyal and $B$. aegyptiaca vegetation (Elnaiem et al. 2001, Hassan et al. 2008). In village habitats in eastern Sudan, the season for peak transmission has not been well studied, although Hassan et al. (2004) reported high rates of $P$. orientalis infected with $L$. donovani in villages.

The occurrence of $P$. papatasi, $P$. bergeroti, $P$. duboscqi and P. saevus in the White Nile area is also of epidemiological interest. P. papatasi, $P$. bergeroti and $P$. duboscqi are sympatric in a different part of Sudan (Elnaiem et al. 1997, Lambert et al. 2002, Hassan et al. 2007). P. papatasi is a known vector of the Leishmania major species that causes cutaneous leishmaniasis in a different part of the country (El-Hassan \& Zijlstra 2001), while $P$. bergeroti has been implicated as a vector of L. major in the Sahara (Seccombe et al. 1993). P. $d u$ boscqi has been reported to be involved in transmission of L. major in neighbouring countries, such as Ethiopia (Balkew et al. 2002) and Kenya (Beach et al. 1984), whereas $P$. saevus has been suspected to be a vector of L. tropica in Yemen (Daoud et al. 1989) and Ethiopia (Gebre-Michael et al. 2004).

In this study, $P$. orientalis was collected at a density varying from 2.6-10.3 and 0.3-1.7 per light trap in the woodland and village, respectively. Due to the variations in the numbers of traps, the kinds of traps (light and oil traps) and the collection schedules, no statistical comparisons were made between the abundance of $P$. orientalis in the woodland and the village. Taking into account the difference in relative abundance between the village and the woodland and the distance between the two $(2-6 \mathrm{~km})$, it is possible to have a "green bridge" that allows successive colonisation (metapopulational structure), where the woodlands are Phlebotomus source populations and the domestic habitats (the village) are sink populations (Salomon et al. 2008). This fact could have consequences for understanding the dynamics of transmission and risk and for the design of prevention and control measures (i.e., buffer zones), including the distance to the woodland and the habits of the human population.

In this study, no Leishmania infection was detected in the $311 P$. orientalis females or in the 112 females of other Phlebotomus species that were dissected (P. papatasi, P. bergeroti, P. duboscqi, P. saevus and P. rodhaini). This result could be due to low infection rates of Leishmania in sandflies during the time of the surveys (May-June) and/or focal transmission of Leishmania parasites in this area. However, parous rates of the $P$. orientalis females in the woodland and the village habitats were relatively high ( $64.8 \%$ and $63.3 \%$, respectively) and thus the chance of identifying natural Leishmania infection in sandflies would be likely. In eastern Sudan, Hassan et al. (2008) reported an 8.6\% rate of L. donovani infection in $P$. orientalis during the same month. Therefore, a large number of sandflies obtained in different seasons of the year should be dissected to detect Leishmania infections, as this will increase the chance of detecting infected females. Otherwise, a polymerase chain reaction (PCR)-based technique could be used to detect Leishmania in sandflies because it can be used to screen large numbers of specimens.
A relatively moderate number of fed and gravid/semigravid female sandflies were recorded in the woodland collection. This finding might suggest that $P$. orientalis flies remain near their hosts after feeding. Moreover, it might also suggest that this species feeds outdoors on animals (wild animals and/or domestic animals) in the woodland habitat, where the animals are likely to live. Some families from the villages adjacent to the woodland habitat studied here form seasonal settlements in the summer during the low discharge of the White Nile River. In these settlements, large numbers of cattle are kept in fenced areas about 5-10 m from houses. These families also keep goats, sheep, donkeys and dogs. These animals could be a suitable source of blood feeding for $P$. orientalis. A similar observation has also been made for P. orientalis in Ethiopia by Gebre-Micheael et al. (2010). The authors reported that $P$. orientalis prefers bovines to humans for its blood meals. Furthermore, as we do not know the threshold for transmission, we could not measure the risk in the village, but we can measure the risk of effective contact between humans and vectors.

Despite the past outbreaks of VL in the study area, a detailed epidemiological investigation in the region to reveal the exact distribution and magnitude of the transmission of the disease is lacking. It is possible that the VL cases previously reported were hospital-based records. Therefore, studies on the seasonal abundance and distribution of $P$. orientalis are needed to elucidate the risk of maximum transmission of Leishmania parasites in the area. In addition, investigation of the infection rates of Leishmania parasites in sandfly vectors by dissecting large numbers of sandflies sampled over a longer time and covering different seasons of the year is needed to determine the transmission season of the disease in the area.

\section{ACKNOWLEDGEMENTS}

To the people of Kadaba and Eid Umesish villages and Prof MM Mukhtar (Institute of Endemic Diseases, University of Khartoum), for valuable help during this study.

\section{REFERENCES}

Abonnenc E, Minter DM 1965. Bilingual key for the identification of sandflies of the Ethiopian region. Cahiers ORSTOM Entomol Med 5: 1-63.

Ahmed MAM, Suleman SM, Kordofani AAY, Mustafa MD 1988. Outbreak of visceral leishmaniasis in the western bank of the White Nile-Sudan, report and clinical study. East Afr Med J 65: 824-828.

Añez N, Tang Y 1997. Comparison of three methods for age-grading of female Neotropical phlebotomine sandflies. Med Vet Entomol 11: 3-7.

Ashford RW, Seaman J, Schorcher J, Pratlong F 1992. Epidemic visceral leishmaniasis in southern Sudan: identity and systematic position of the parasites from patients and vectors. Trans $R S O c$ Trop Med Hyg 86: 379-380.

Balkew M, Gebre-Michael T, Berhe N, Ali A, Hailu A 2002. Leishmaniasis in the middle course of the Ethiopian Rift Valley. II. Entomological observations. Ethiop Med J 40: 271-282.

Beach R, Kiilu G, Kendricks L, Oster C, Leeuwenberg J 1984. Cutaneous leishmaniasis in Kenya. Transmission of Leishmania major to man by the bite of Phlebotomus duboscqi. Trans $R$ Soc Trop Med Hyg 78: 747-751. 
Daoud W, Rioux JA, Delabre-Belmonte A, Dereure J, Rageh HA 1989. Écoépidémiologie des leishmanioses viscérales et cutanées en République Arabe du Yémen. III. Inventaire et dynamique des phlébotomes. Bull Soc Path Exot 82: 669-677.

El-Hassan AM, Zijlstra EE 2001. Leishmaniasis in Sudan. Cutaneous leishmaniasis. Trans R Soc Trop Med Hyg 95 (Suppl. 1): S1-S17.

Elnaiem DA, Conners S, Thmoson M, Hassan MM, Hassan KH, Aboud MA, Ashford RW 1998. Environmental determinants of the distribution of Phlebotomus orientalis in Sudan. Ann Trop Med Parasitol 92: 877-887.

Elnaiem DA, Hassan HK, Ward RD 1997. Phlebotomine sandflies in a focus of visceral leishmaniasis in a border area of eastern Sudan. Ann Trop Med Parasitol 91: 307-318.

Elnaiem DA, Hassan MM, Maingon R, Nureldin GH, Mekawi AM, Miles M, Ward RD 2001. The Egyptian mongoose, Herpestes ichneumon, is a possible reservoir host of visceral leishmaniasis in eastern Sudan. Parasitology 122: 531-536.

Elnaiem DA, Osman OF 1998. Evidence for active transmission of visceral Leishmaniasis within a village in eastern Sudan. Acta Trop 71: 305-309.

Gebre-Michael T, Balkew M, Ali A, Ludovisi A, Gramiccia M 2004. The isolation of Leishmania tropica and L. aethiopica from Phlebotomus (Paraphlebotomus) species (Diptera: Psychodidae) in Awash Valley, northeastern Ethiopia. Trans R Soc Trop Med Hyg 98: 64-74.

Gebre-Michael T, Balkew M, Berhe N, Asrat Hailu A, Mekonnen Y 2010. Further studies on the phlebotomine sandflies of the kala-azar endemic lowlands of Humera-Metema (north-west Ethiopia) with observations on their natural blood meal sources. Parasit Vec 3: 6 .

Hassan MM, Elamin EW, Mukhtar MM 2008. Isolation and identification of Leishmania donovani from Phlebotomus orientalis, in an area of eastern Sudan with endemic visceral leishmaniasis. Ann Trop Med Parasitol 102: 1-3.

Hassan MM, Elraba'a FMA, Ward RD, Maingon R, Elnaiem DA 2004. Detection of high in-village transmission of Leishmania donovani in eastern Sudan. Acta Trop 92: 77-82.

Hassan MM, Widaa SO, Ibrahim MA, Abu Shara R, Osman OM, Numairy MSM, El-Khidir ETM 2007. Studies on the ecology of sandflies (Diptera: Psychodidae) in Sudan: the first records of Phlebotomus orientalis and P. rodhaini in northern Sudan. Ann Trop Med Parasitol 101: 653-655.
Hoogstraal H, Heyneman D 1969. Leishmaniasis in Sudan Republic. 30. Final epidemiological Report. Am J Trop Med Hyg 18: 1091-1210.

Khalil EAG, Musa AM, Elgawi SH, Meshasha A, Gamer Eldawla I, El-Hassan MO, Eljaleel KA, Younis BM, Elfaki ME, EL-Hassan AM 2008. Revival of a focus of visceral leishmaniasis in central Sudan. Ann Trop Med Parasitol 102: 79-80.

Kirk R, Lewis DJ 1951. The phlebotomine of the Ethiopian region. Trans $R$ Entomol Soc London 102: 383-510.

Lambert M, Dereure J, El-Safi SH, Bucheton B, Dessein A, Boni M, Feugier E, Dedet JP 2002. The sandfly fauna in the visceralleishmaniasis focus of Gedaref in the Atbara-River area of eastern Sudan. Ann Trop Med Parasitol 96: 631-636.

Lane RP, Fritz GN 1986. The differentiation of the leishmaniasis vector Phlebotomus papatasi from the suspected vector $P$. bergeroti (Diptera: Phlebotominae). Syst Entomol 11: 439-445.

Magnarelli LA, Modi GB, Tesh RB 1984. Follicular development and parity in phlebotornine sand flies (Diptera: Psychodidae). J Med Entomol 21: 681-689.

Pesson B, Madulo-Leblond G, Killick-Kendrick M, Tang Y, KillickKendrick R 1994. The armature in the genital atrium as a new taxonomic character distinguishing females of Phlebotomus papatasi and P. duboscqi (Diptera: Psychodidae). Ann Trop Med Parasitol 88: 539-542.

Quate LW 1964. Leishmaniasis in Sudan Republic. 19. Phlebotomus sandflies of the Paloich area in the Sudan (Diptera: Psychodidae). J Med Entomol 1: 213-268.

Salomon OD, Quintana MG, Zaidenberg M 2008. Urban distribution of Phlebotominae in a cutaneous leishmaniasis focus, Argentina. Mem Inst Oswaldo Cruz 103: 282-287.

Satti MH 1958. Kala azar in the Sudan and tropical Africa. Proceedings of the six international congress on Tropical Medicine and Malaria 3: 5.

Seccombe AK, Ready PD, Huddleston LM 1993. A catalogue of Old World Phlebotomine sandflies (Diptera: Psychodidae: Phlebotominae). Occasional papers on systematic entomology 8, Department of Entomology, The Natural History Museum, London, 57 pp.

Wickens GE 1991. Natural vegetation. In GM Craig, The agriculture of the Sudan, Oxford University Press, London, p. 54-67.

Zijlstra EE, El-Hassan AM 2001. Leishmaniasis in Sudan. Visceral leishmaniasis. Trans R Soc Trop Med Hyg 95 (Suppl. 1): S27-S58. 